Brocar, 19 (1995) 189-209

\title{
EMBLEMAS Y LEMAS DE LAS SOCIEDADES ECONÓMICAS DE AMIGOS DEL PAÍS. ANÁLISIS DE UN DISCURSO DE INTENCIONES
}

\author{
Marc Marti*
}

\begin{abstract}
RESUMEN: El artículo que sigue presenta un nuevo enfoque sobre las Sociedades Económicas de Amigos del País. Más allá de los trabajos históricos clásicos, aunque figura un breve resumen cronológico del movimiento de creación de esas nuevas instituciones, se trata de considerar las Sociedades Económicas en su dimensión cultural. Con este propósito analizaremos los emblemas y lemas de esas asociaciones en relación con el contexto cultural económico y social de la época.

En los resultados emergen cuatro elementos esenciales:

- La presencia de un código cultural clásico de referencia, el de la cultura grecolatina.

- Un segundo código cultural, nuevo, el de la Ilustración con la fe en la educación, el progreso y la razón

- Una perspectiva urbana sobre la actividad económica, considerada a partir del punto de vista de la clase propietaria.

- Una actitud conservadora a pesar de la reivindicación de la idea de progreso.
\end{abstract}

ABSTRACT: The following article proposes a new approach to the Economic Societies of the Friend of the Countryside. Basing our study on classical studies, so as to give the necessary bistorical background to their foundation, we will then consider the cultural dimension in these Economic Societies. To that effect we will analyse the emblems and mottoes of these Societies in reference to the cultural, economic and social context of the time.

The results will bring to light four essential elements:

- the presence of a classical cultural code of reference, namely the Greek-latin cultural pattern

- another new cultural code, the code prevalent in the Age of Enlightenment which valued Education, Reason and Progress

- an urban perspective on economic activity, considered from the angle of the ruling, landowning class

- a conservative attitude, despite claims to progresive standpoints.

* Doctor en Historia. Profesor de la Universidad de Toulon, Département de Civilitation Hispanique 
Indudablemente, hablar de la segunda parte del siglo XVIII español, es hablar de las Sociedades Económicas de Amigos del País. Las investigaciones de Paula y Jorge Demerson, Aguilar Piñal y Gonzalo Anes, entre las más clásica o, las recientes monografias, como la tesis de Velázquez Martínez sobre la Sociedad de Murcia, enfocan sobre todo el proceso de formación de las Sociedades Económicas, sus relaciones de filiación con las Academias de principios de siglo así como sus componentes sociales ${ }^{1}$. El contenido de los informes, los temas de los concursos propuestos por las Sociedades, también cuentan con amplios estudios ${ }^{2}$.

Proponemos aquí un nuevo enfoque sobre esas instituciones, poniendo de relieve la rapidez de su creación, el origen social de los fundadores y, sobre todo, su génesis urbana. A partir de este breve resumen histórico, se podrá acometer un estudio original de los emblemas y lemas de las Sociedades Económicas.

No existe en efecto, según hemos averiguado hasta ahora, un estudio global sobre las Sociedades Económicas y el discurso que ellas mantenían sobre la realidad de su época. Desde esta perspectiva, el análisis de los emblemas y lemas puede ser provechoso para el historiador: a través de este lenguaje figurado, las nuevas instituciones intentaron marcar su originalidad, su origen y su participación en un movimiento de envergadura nacional. El estudio que sigue permitirá determinar cuáles eran los códigos representativos, las formas que estructuraban el pensamiento de las Sociedades Económicas y eventualmente el de las Luces hispanas. Pero más allá del análisis formal, será preciso definir la visión que dichas instituciones tenían de la economía, que teóricamente constituía su campo de reflexión y de actuación.

La dinámica de la Sociedades Económicas de Amigos del País:

UNOS ELEMENTOS DE LA GÉNESIS

No se trata de explicar el fenómeno global de creación de las Sociedades Económicas de Amigos del País, ni aludir a las realizaciones llevadas a cabo por las nuevas instituciones, ya que se trata de temas ampliamente estudiados y comentados. Sin embargo incidiremos en algunos temas de especial importancia para el análisis de los emblemas y lemas que presentaremos a continuación.

El movimiento fundacional centralista y espontáneo. Los datos que utilizamos están sacados del libro Las sociedades Económicas de Amigos del País en el siglo XVIII, Guía del investigador. Paula y Jorge Demerson junto con Aguilar Piñal censaron ciento siete demandas de creación de Sociedades de 1763 a 1808. Diecinueve no tuvieron resultado o no fueron aprobadas. Se puede entonces

1. DEMERSON, P.; DEMERSON, J.; AGUILAR PIÑAL, F. 1974.; VELÁZQUEZ MARTÍNEZ, 1989. ANES, G. 1972.

2. Recordamos aquí los trabajos de VERGNES, R. y de LUCIENNE, D. 1969. 
suponer, manejando los datos con la misma prudencia que los citados autores, que, entre 1765 (Vergara) y 1802 (Ocaña), se crearon ochenta y ocho Sociedades en España.

Precedido por las Sociedades de Vergara (1765), Tudela de Navarra y Baeza (1775), el movimiento nacional siguió con la fundación de la Real Sociedad Económica de Amigos del País de Madrid y la difusión del Discurso sobre el Fomento de la Educación Popular de Campomanes. Las solicitudes de creación afluyeron rápidamente a la Corte, como se puede comprobar en los datos que siguen.

$\begin{array}{ccc}\begin{array}{c}\text { Cronología de las demandas de creación de Sociedades Económicas } \\ \text { Períodos }\end{array} & \text { Número de demandas } & \text { Plazo medio de aprobación } \\ 1775-1779 & 36 & 2 \text { años y } 4 \text { meses } \\ 1780-1784 & 21 & 2 \text { años y } 11 \text { meses } \\ 1785-1789 & 24 & 1 \text { año y } 7 \text { meses } \\ 1790-1794 & 2 & 2 \text { años } \\ 1795-1799 & 2 & \text { año en curso } \\ 1800-1805 & 2 & \text { año en curso } \\ \text { Total: } & 88 & -\end{array}$

Los plazos de aprobación son bastante cortos, ilustrando la voluntad del gobierno de fomentar el desarrollo de las nuevas instituciones. Cronológicamente, el movimiento corresponde casi perfectamente con los últimos quince años del reinado de Carlos III, reduciéndose a seis las creaciones durante el de Carlos IV. En efecto, al cabo de quince años, la mayoría de los centros urbanos que lo habían deseado, ya tenían su Sociedad Económica aunque subsistían excepciones mayores (Burgos, Cádiz, Bilbao, Barcelona). Las Sociedades que ya funcionaban conocieron bajas en sus actividades a mediados de los años ochenta. El 28 de junio de 1786, el Consejo de Castilla empezó a informar sobre las razones de la decadencia general de las Sociedades. Las que participaron en el informe explicaron su decadencia por la excesiva multiplicación de Sociedades, la formación de partidos que provocaban tensiones en el seno de las asociaciones, el ambiente desfavorable debido a la hostilidad de unos sectores de la sociedad local, la indiferencia general, la mediocridad de parte de sus miembros, la falta de dinero, las trabas legislativas y el desinterés del Estado, el aspecto utópico de la mayoría de los proyectos, la ausencia de una infraestructura suficiente para realizarlos y por fin, un absentismo elevado y una evidente apatía en la mayoría de las asambleas ${ }^{3}$.Tras de la muerte de Carlos III, el

3. ANES, G. 1972: p 39 y VELÁZQUEZ MARTÍNEZ, 1989, que trata el problema en su conjunto, pp. 120-121. 
cambio ministerial aceleró sin duda la decadencia de las Sociedades que, a partir de 1790 , fueron alejándose cada vez más de la política gubernamental. El impacto de la revolución francesa, que cortó cualquier tentativa reformista, no hizo sino empeorar la situación. Las estructuras pervivieron pero estaban ya bastante lejos de la idea que había presidido a su formación.

El origen social y espacial de los fundadores. Gonzalo Anes ya apuntó que los fundadores de las Sociedades eran en su mayoría beneficiarios de la renta de la tierra, como también los que tenían algún interés en la producción manufacturera. Se trataba de nobles, miembros del clero, o plebeyos. La unión entre los diferentes estamentos se explica por una coyuntura económica favorable, reuniéndolos la convergencia de sus intereses en las Sociedades Económicas ${ }^{4}$. Campomanes recordaba a los nobles que "La Sociedad Económica ha de ser compuesta, para que pueda ser útil, de la nobleza más instruida del país. Ella es la que posee las principales y más pingües tierras y tiene el principal interés en fomentar la riqueza del pueblo, cuya industria da valor a sus posesiones"s. Sin embargo no todas las creaciones fueron espontáneas. El Estado podía fácilmente, mediante unos funcionarios o intendentes, crear una Sociedad como fue por ejemplo el caso en Murcia ${ }^{6}$.

Por otra parte, la aparición de Sociedades Económicas suponía la existencia de una ciudad bastante importante, donde residían los propietarios y beneficiarios de la renta agraria. Esta ciudad poseía las más veces Academias, prueba de su dinamismo intelectual, lo que demuestra, por si fuera necesario, que las Sociedades no fueron creaciones ex nibilo sino que fueron el fruto de estructuras que ya existían antes del Discurso de Campomanes, que vino, en la mayoría de los casos, a concretar las aspiraciones de estos grupos ilustrados ${ }^{7}$.

El establecimiento de las Sociedades respetó la jerarquía urbana. Aunque en Madrid se pensaba "que conviene no sólo aprobar, sino promover el establecimiento, así en las capitales como en las ciudades de segundo orden, y aun en las villas que lleguen a mil vecinos de población" ", en la realidad, el comportamiento de los centros urbanos mayores, que ya poseían una asociación, distó mucho de ser favorable a la multiplicación de Sociedades en las pequeñas aglomeraciones. Un ejemplo de esta actitud y del desprecio que se emanaba de las ciudades respecto a los "pueblos" es la carta que Santiago de Compostela dirigió contra éstos afirmando que "faltos de conocimientos necesarios e imposibilitados casi de adquirirlos, y siendo preciso que sus miras y sus ideas, por limitarse a un corto país, sean poco generales, están necesariamente expuestos a muchos errores

4. ANES, G. 1972, pp. 24-25.

5. RODRÍGUEZ DE CAMPOMANES, P. 1975.

6. ANES, G. 1972, p. 24, VELÁZQUEZ MARTÍNEZ, 1989, p. 95 y DEMERSON, J. 1969, p. 20.

7. VELÁZQUEZ MARTÍNEZ, 1989, pp. 43-44.

8. VELÁZQUEZ MARTÍNEZ, 1989, p. 177. 
políticos y a molestar el gobierno con representaciones y recursos poco juiciosos y a veces contradictorios, los cuales, ya que no producen otro mal efecto, desacreditan siempre a todas las Sociedades indistintamente". Multiplicar los ejemplos sería innecesario para afirmar que se produjo una lucha jerárquica, una lucha para el prestigio que revela las tensiones que existían en la red urbana entre las grandes y pequeñas aglomeraciones, y acaso, -pero el hecho queda por demostrar-, tensiones sociales.

Este breve análisis histórico de la fundación de las Sociedades Económicas permite apuntar unos cuantos elementos interesantes. Las nuevas instituciones fueron rápidamente creadas, demostrando que la idea de Campomanes había sido recibida con entusiasmo. Pero es obvio que en un contexto económico favorable, el gobierno canalizaba de hecho gran parte de las preocupaciones ilustradas que ya se habían manifestado en la creación de Academias. Ante todo fueron las grandes ciudades, residencia de los propietarios y beneficiarios de la renta de la tierra, las que encabezaron el movimiento, oponiéndose a veces con fuerza a la creación de Sociedades en las pequeñas aglomeraciones.

UN DISCURSO DE INTENCIÓN: LEMAS Y EMBLEMAS DE LAS SOCIEDADES ECONÓMICAS

Las Sociedades Económicas siempre fueron enfocadas como fenómenos históricos, sociales y económicos. Un aspecto poco considerado fue su dimensión cultural. Proponemos pues analizar la ideología de dichas instituciones a través de los objetos culturales que mejor las caracterizan: sus lemas y emblemas.

El corpus. Dijimos anteriormente que según la Guía del investigador, sólo ochenta y ocho sociedades obtuvieron la aprobación del Consejo de Castilla. De este conjunto hemos seleccionado las Sociedades que poseían a la vez un lema y un emblema, formando el grupo siguiente.

\section{Lemas de las Sociedades Económicas}

Ciudades:

Alaejos . . . . . . . . . A socorrer la pobreza y desterrar la pereza

Avila . . . . . . . . . . Sociedad Económica de Avila

Baena . . . . . . . . . Sociedad Económica de Baena

Baeza . . . . . . . . . . Pro patria potius mori quam foedari

Ciudad Rodrigo . . . . . . Concordia et labore

Córdoba . . . . . . . . Nec decus auriferae cessavit Cordoba terrae

Cuenca ......... Al Bien Público

Granada ........... Admiranda dabunt levium spectaculum rerum 
MARC MARTÍ

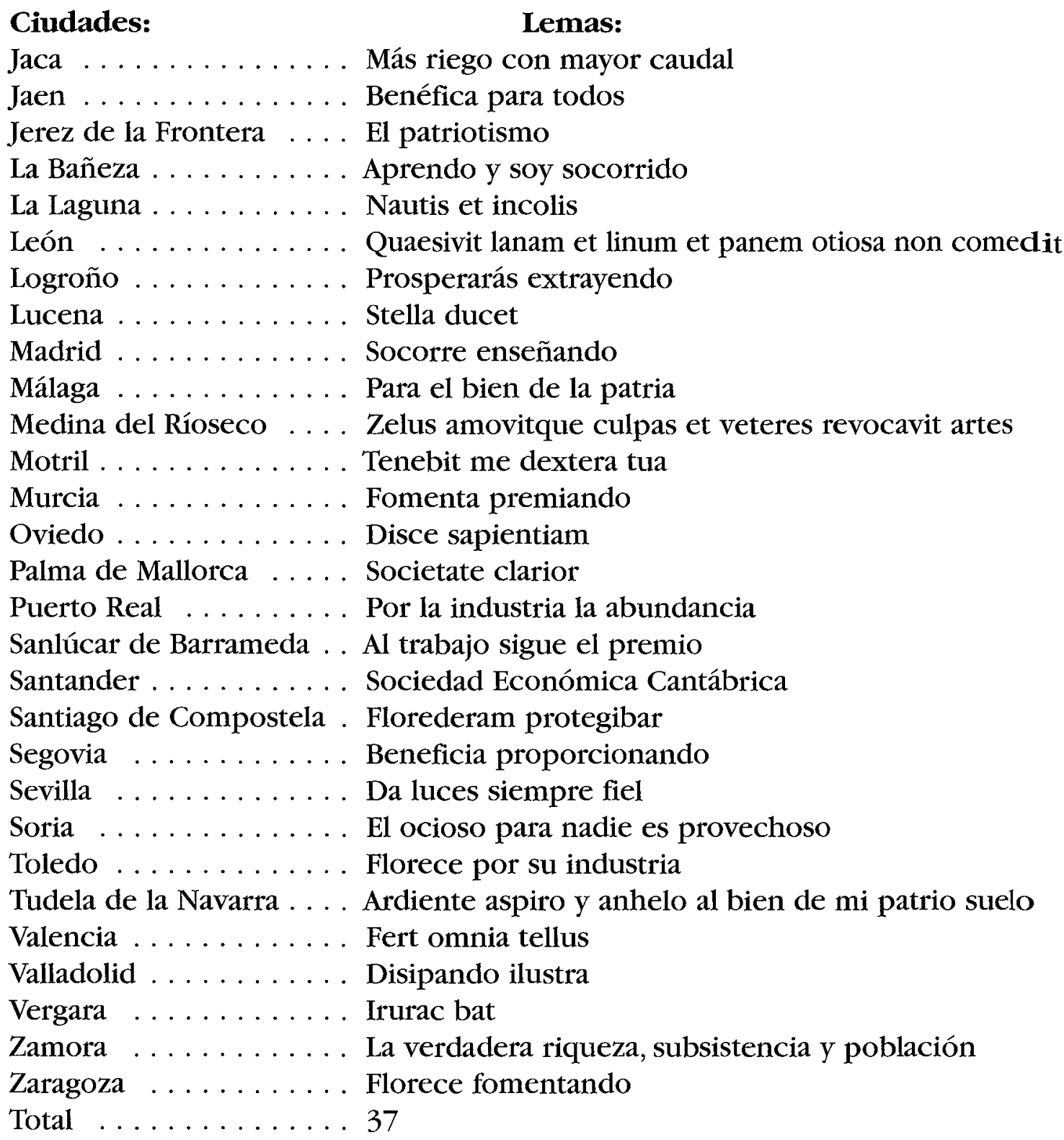

Este corpus plantea tres problemas de heterogeneidad. Apuntamos ya que la mayoría de los lemas son en castellano (24). El resto aparece en latín (12) y sólo uno en idioma regional: el de la Sociedad Vascongada.

Según Arias Saavedra, el latín revelaría el carácter provinciano de las asociaciones que lo utilizan y la pretensión de distinguirse de las demás ${ }^{10}$. En efecto, el latín ya no era un idioma elitista desde el siglo XVI; en el siglo de las Luces, esta lengua es sinónimo de élite sólo en el norte de Europa ${ }^{11}$. Veremos sin embargo que unos cuantos lemas en latín se refieren a la Biblia. Sin embargo conservamos esta heterogeneidad de idiomas para el análisis del conjunto de los lemas.

10. Cit. en VELÁZQUEZ MARTÍNEZ, 1989, p. 99.

11. CHAUNU, P. 1971, p. 227. 
El segundo problema, más importante, es el de la definición de los objetos que vamos a estudiar. En efecto, cómo considerar los grupos lema/imagen -empleamos este término de manera provisional- que representan las Sociedades Económicas. Si no hay ninguna duda en cuanto a la parte lingüística -se trata de lemas- queda una ambigüedad en cuanto a la parte icónica. Para designarla, los Demerson y Aguilar Piñal utilizan las palabras "escudos", considerando implícitamente que forman parte de las representaciones heráldicas. Velázquez Martínez habla de "sellos" o "emblemas", pero en los informes de las propias Sociedades también se habla de "medalla". Estas imprecisiones reflejan la heterogeneidad de los signos icónicos. No se puede negar la influencia de la heráldica, en particular en la asociación de la imagen con un lema. Pero en la mayoría de los casos, el escudo -considerando la.palabra en su sentido heráldico- desapareció, así como las armas y el timbre. Puede conservarse un marco circular, lo que explicaría el empleo de "medalla" (como es el caso para Murcia o Ávila) u otras veces éste desaparece totalmente (León). Unas cuantas Sociedades conservan el escudo completo, que figura las armas de la ciudad o villa (Puerto Real), pero en este caso es completado por otros elementos que representan las actividades económicas (arado, campesino, etc.). Finalmente, cuando elementos tradicionales de la heráldica aparecen es únicamente para evocar la ciudad ${ }^{12}$. En lo que sigue, usaremos la palabra emblema, siguiendo la definición que da la Academia "jeroglífico, símbolo o empresa en que se representa alguna figura, y al pie de la cual se escribe algún verso o lema que declara el concepto o moralidad que encierra"13.

Metodología. Utilizaremos los trabajos de Roland Barthes sobre la publicidad y los de Louis Porcher sobre la semiótica de la imagen, considerando que emblemas y lemas forman un conjunto portador de mensajes "que puede ser objeto de un análisis semiótico, de la misma manera que las imágenes utilizadas en las comunicaciones de masa" ${ }^{14}$. Es obvio que existen bastantes diferencias entre las fotografias publicitarias y los objetos semióticos que nos interesan; sin embargo poseen "una esencia común que puede justificar un enfoque idéntico: en los dos casos se trata de imágenes acompañadas de leyendas" ${ }^{15}$. El método que vamos a seguir, definido por Roland Barthes, admite la existencia de tres mensajes:

- Un mensaje lingüístico, constituido por el lema. Sólo en el caso de la Sociedad de Lucena, el lema está separado del emblema ${ }^{16}$. En otros dos casos (Motril y la Bañeza), aparece, se puede utilizar este anacronismo, como un boca-

12. DEMERSON, P., DEMERSON, y J. AGUILAR PIÑAL, F. 1974;VELÁZQUEZ MARTÍNEZ, 1989, p. 99.

13. Diccionario de la Real Academia Española.

14. BARTHES, R. pp. 40-51; PORCHER, L. 1976; SOUBEYROUX, J. 1981, pp. 107-137.

15. SOUBEYROUX, J. 1981, p. 109.

16. Es probable que Aguilar Piñal y Demerson sólo pudieron observar un esbozo del emblema donde no se había inscrito todavía el lema, es por lo menos lo que deja suponer el aspecto basto del dibujo. 
dillo de tebeo: en el interior del emblema, como si fuera pronunciado por un personaj $^{17}$. Los demás lemas aparecen o en el marco o en el exterior, lo que no cambia nada en cuanto a su significación.

- Un primer mensaje icónico, que Barthes denomina literal; corresponde con el significado primero de la imagen, al nivel de la idendificación del signo con el objeto o la escena representada,

- Un segundo mensaje icónico, calificado de simbólico, constituido por las relaciones que se crean entre esos mismos objetos, al nivel cultural o imaginario, fuera del campo puramente icónico.

La función del mensaje lingüístico. El texto de los lemas tiene primero una función de elucidación; siendo la imagen por definición polisémica, "el texto dirige al lector entre los significados, $[\ldots]$ hacia uno solo, muchas veces escogido por antelación"18.

La leyenda de la Bañeza "aprendo y soy socorrido" da a entender al espectador que la actividad del pobre que figura el emblema tiene un propósito pedagógico ("aprendo"), correspondiendo con un esfuerzo filantrópico, que se puede atribuir a la Sociedad ("soy socorrido"). En el "Prosperarás extrayendo" de Logroño se explica la presencia de la cornupia ("prosperarás"), recordando la necesidad de exportación ("extrayendo"), figurada simbólicamente por la presencia de Mercurio, dios mensajero, pero también símbolo de prosperidad. El emblema de Oviedo, que figura el trabajo de las hormigas, asociado con el lema "Disce sapientam", orienta al espectador hacia el valor ejemplar y alegórico del trabajo perpetuo de los insectos.

Otras veces, el mensaje lingüístico completa la imagen. En el caso de Alaejos, se ven dos corazones ceñidos por una banderola en la que se lee "En favor de la patria", esta medalla está completada por el lema "A socorrer la pobreza y desterrar la pereza". Aquí no hay una relación directa entre el mensaje lingüístico y la imagen, pero la asociación de los dos elementos implica una significación más amplia de la que pudieran tener la imagen o el lema solos.

No se puede sin embargo limitar el mensaje lingüístico a las funciones de complemento y elucidación de la imagen. En efecto, si unos cuantos términos son totalmente "transparentes" ("riego", "lanam" etc.), otros encierran diferentes connotaciones: "stella ducet" recuerda a la vez la estrella que guió a los Reyes, pero también la estrella (o luz) de la Razón seguida por los ilustrados. De la misma manera, en el lema de León, los sentidos de "panem" (el pan, acusativo) se superponen: en un primer nivel, se trata de un alimento, pero el objeto remite al

17. La Bañeza: Se ve a un pobre que trabaja la lana y que dice "Aprendo y soi (sic) socorrido".

18. BARTHES, R. pp. 43-45. 
mundo simbólico. Es a la vez el alimento sagrado en la religión católica y el alimento básico del pobre, del obrero, del campesino, premio de su trabajo.

El mensaje lingüístico pues, puede reducir las interpretaciones de la imagen o completar su significado o crear polisemia, refiriéndose a varios elementos simbólicos.

Análisis de las formas lexicográficas. Los treinta y siete lemas forman un conjunto de ciento cincuenta signos. Apartando las preposiciones, artículos, posesivos, pronombres, quedan noventa y siete signos $^{19}$, que clasificamos en once campos lexicográficos y semánticos.

1.Actividad humana, economía, trabajo (20 ocurrencias)

1.1. Agricultura: riego, tellus, suelo, terrae

1.2. Industria: industria (2), artes, lanam, linum, quaesivit

1.3. Otros: $\quad$ labore, trabajo, extraer, nautis, económica (3), subsistencia, comedit, panem

2. Progreso, desarrollo, prosperidad (16 ocurrencias):

fomentar (2), mayor, más, caudal, riqueza, prosperarás, abundancia, proporcionar, florece (2), floreveram, provechoso, beneficiar, fert, auriferae.

3. Calidades morales/defectos, sentimientos (12 ocurrencias):

pereza, foedari, culpas, zelus, sapientiam, fiel, ocioso, otiosa, ardiente, decus, anhelo, aspiro

4. Unión, colectividad(es) (12 ocurrencias):

Córdoba, Sociedad (3), Societate, concordia, público, irurac bat, incolis, población, omnia, todos,

5. Premio/beneficiencia, don (11 ocurrencias): socorrer (2), socorrido (1), bien (2), benéfica, premiar, premio, protegibar, dabunt, da.

6. Enseñanza (7 ocurrencias):

aprendo, enseñando, ilustra, luces, admiranda, spectaculum, verdadero.

7. Luz/ilustración ( 5 ocurrencias):

Stella, clarior, luces, ilustra, levium rerum

8. Ser/Estar (5 ocurrencias):

es, soy, siempre, (non) cessavit, veteres

9. Guía (5 ocurrencias):

Tenebit, ducet, disce, sigue, dextera

10. Patria (4 ocurrencias):

patria (2), patriotismo, patrio

11. Vencer un obstáculo ( 4 ocurrencias):

desterrar, revocavit, disipando, amovitque

19. O grupos indisociables: dans "levium rerum", "rerum" no tiene sentido si se separa del adjetivo. Conservamos también el lema en vasco integralmente. 
Considerando que los campos 6 (Enseñanza) y 7 (Luz/ilustración) son complementarios, siendo la luz una metáfora de la enseñanza y del saber, ya se pueden esbozar las articulaciones del discurso subyacente en el conjunto de los lemas. El campo 1 aparece como el conjunto de las actividades (objetos) en las que se van a ejercer las acciones de las Sociedades. El campo 2 representa los objetivos que se quieren alcanzar (progreso, desarrollo, prosperidad). Los campos 5, 6, 7, 9, 11 representan pues los actores y beneficiarios del trabajo de las Sociedades.

Se puede notar la ausencia casi total de referencia a la religión en los lemas, aunque "Stella ducet" podría recordar el episodio del nacimiento de Cristo; cosa cuanto más sorprendente que buena parte de las Sociedades tuvieron por inspiradores miembros del clero ${ }^{20}$. Obviamente es una prueba de la novedad de las Luces; durante el siglo XVIII, el pensamiento económico experimenta un proceso de renovación, que le da más autonomía respecto a las reflexiones religiosas.

El conjunto de los noventa y siete signos se inscribe en una estructura única, una utopía de viaje al progreso gracias a la educación (enseñanza y premio). En efecto, la mayoría de las Sociedades crearon escuelas especializadas (sobre todo en trabajo del textil y el dibujo). En Córdoba, fue una Casa-Colegio para las niñas; en Motril, una escuela de Agricultura. Cabe recalcar que, de manera general, el vocabulario usado por las asociaciones debe mucho al léxico de la enseñanza: "clases de Agricultura, clases de Física" etc. Aquí encontramos una idea repetida en España como en el resto de Europa; la educación se considera como una panacea, puede solucionar cualquier problema social o económico. Este sistema de enseñanza que las Sociedades intentaron establecer era original. Inspirado por Campomanes, reivindicaba el pragmatismo, la técnica más que la teoría, ya que se destinaba al pueblo, siguiendo claramente la sentencia del ministro que afirmaba que es "más útil en el orden civil al género humano la invención de las agujas de coser: instrumento de tanto uso que debe preferirse a la lógica de Aristóteles, y a un gran número de sus comentadores, los cuales han sido en España más comunes que las fábricas de agujas" ${ }^{21}$. De cierta manera, los Amigos del País fueron precursores de la enseñanza técnica moderna. En España como en el resto de Europa, "la tecnología pasa a otra área. Del aprendizaje por la vista y el oído, se pasa al libro -manuales y tratados- de la enseñanza mutua a la enseñanza institucionalizada"22.

Cabe también notar que cuando aparece un beneficiario en los lemas, siempre se trata de una colectividad (patria o público). Esta idea es constante en el pensamiento de las Luces españolas, sobre todo durante el "primer periodo"

20. Aproximadamente el veinticinco por ciento de las Sociedades tienen por origen un miembro del clero. Véase nuestro trabajo de tesis. MARTí, M. 1994, chapitre 5.

21. RODRÍGUEZ DE CAMPOMANES, P. 1975, p 35.

22. CHAUNU, P. 1971, p. 189. 
(hacia mediados de los años 1780). La noción de interés colectivo será luego cada vez más sustituida por la de interés individual, más característica del "segundo periodo" 23 . Nada sorprendente en nuestro caso que domine la noción de interés público puesto que la mayoría de los lemas fueron elaborados antes de 1785 .

En cuanto al tiempo de los verbos, se nota que el presente está utilizado en casi la mitad de los lemas (16 de los 34 que contienen un verbo). Los demás tiempos se reparten de la manera siguiente: gerundio (6), pasado (6), infinitivo (4), futuro (2). La predominancia del presente se explica por el tipo mismo del mensaje lingüístico. A menudo el lema tiene por meta enunciar una calificación de la Sociedad: "Socorre enseñando" (Madrid); en este caso, el gerundio completa el presente. Aparece también el presente como la afirmación de una verdad general, que puede tener la forma de un refrán o sentencia, como en el caso de Soria "El ocioso para nadie es provechoso"). La alusión al refrán o sentencias utiliza también el pasado: "Nec decus auriferae cessavit Córdoba terrae" (Córdoba); "Zelus amovitque culpas et veteres revocavit artes" (Medina del Ríoseco). Las dos apariciones del futuro muestran la orientación hacia el porvenir. En Granada se trata del proyecto de la Sociedad "Admiranda dabunt levium spectaculum rerum". En Logroño, parece que el lema se dirige a la ciudad, indicándole el camino que seguir "Prosperarás extrayendo". La forma de este último lema señala la importancia de las personas verbales.

Entre los treinta y cuatro verbos utilizados, se encuentran 5 primeras personas, dos segundas personas, 27 terceras personas. El empleo de la segunda persona es muy interesante, supone un público al que se debe dirigir un mensaje, pero en los dos casos se trata casi de una orden: en "Disce sapientam" se utiliza el imperativo y en "Prosperarás extrayendo" se da una clase de economía. El empleo de la primera persona tiene dos sentidos. Se utiliza en una especie de autodefinición como "Ardiente suspiro y anhelo al bien de mi patrio suelo" (Tudela de la Navarra) o se trata de un monólogo dirigido al lector "Aprendo y soy socorrido" (La Bañeza).

También se podría notar la ausencia casi completa de referencias directas a la religión en los lemas, cuanto más que buena parte de las Sociedades fueron creadas o protegidas por miembros del clero $^{24}$. La economía en el siglo XVIII se aparta de las reflexiones teológicas y morales para adoptar un punto de vista más científico. Sin embargo, el hecho de que tres sociedades -Léon, Motril, Oviedo ${ }^{25}$ hayan escogido por lema un extracto de la Biblia demuestra que el triunfo de la visión "científica" es todavía incompleto y que se trata de un proceso lento,ina-

23. VERGNES, R. p. 303.

24. Aproximadamente la cuarta parte de la Sociedades Económicas fueron creadas por miembros del clero. Véase nuestro trabajo de tesis, MARTí, M. 1994, chapitre 5.

25. Léon: Proverbios c. 31, v. 13 y v. 28; Motril: Salmos c. 139, v. 10; Oviedo Proverbios c. 4, v. 5; c. 8 , v. 5, c. 30 , v. 24 et 25 
cabado durante la Ilustración. Además, las primeras memorias premiadas por la Sociedad Matritense utilizan los textos sagrados como autoridades o referencias en materia económica ${ }^{26}$. Sin embargo, el análisis de los lemas quedaría incompleto si no se completase con el de los emblemas.

Análisis de los mensajes icónicos: El mensaje icónico literal o imagen denotada. Barthes define este nivel de la imagen como una imagen "inocente", "utópicamente libre de sus connotaciones" 27 o sea el de la identificación del signo con el objeto que representa. Este tipo de lectura es claramente una abstracción necesaria para entender y realizar el análisis. No corresponde de ninguna manera con la realidad de la percepción natural que no hace la distinción entre la lectura objetiva (identificación del signo con el objeto) y subjetiva (identificación del signo con una referencia cultural), sino que realiza los dos actos casi simultáneamente. En la clasificación de las imágenes que sigue obtenemos un conjunto de 335 signos icónicos.

1. Atributos de la agricultura y de la ganadería (62 ocurrencias)

arado (16), hoz (8), árbol (7), labrador (4), horca (3),

espiga de trigo (3), haz (3), rastrillo (2), alquería (2), azadón (2),

oveja (1), ganado (1), racimo de uvas (1), cepa (1),

campo cultivado (1), noria (1), aceituna (1), yugo (1), sembradora (1), morera (1), laya (1), pámpano (1)

2. Elementos ornamentales ( 43 ocurrencias)

banderola (22), friso (5), ramas (4), flor (4), pedestal (3), máscara (3), columna (1), cortina (1)

3. Instrumentos de dibujo (34 ocurrencias)

compás (13), escuadra (9), paleta de pintor (5), regla (4), transportador (3)

4. El progreso y de la abundancia (32 ocurrencias) cornupia (22), caduceo (7), Mercurio (2), granada (1)

5. Atributos de la industria (33 ocurrencias) torna (12), devanadera (6), raedera (3), máquina de cardar (3), bulto de lana (2), lanzadera (2), artesano (2), martillo (2), destral (1)

6. Atributos del entendimiento (28 ocurrencias)

libro (7), globo terráqueo (5), antorcha (5), sol (5), mapa (3), estrella (1), espejo (1), Minerva (1)

26. Véase por ejemplo la memoria de don Miguel Nicolás de Palma, socio de mérito, "Medios de adelantar los pastos sin perjudicar la labranza; de utilizar todas las tierras; tener más hierbas, y otros aprovechamientos; de sembrarlas; segarlas y subrogarlas, según la especie de ganado", Memorias de la Real Sociedad Económica Matritense, Madrid, Imprenta Sancha, t 2, p 1 sq.

27. SOUBEYROUX, J. 1981, p. 122. 
EMBLEMAS Y LEMAS DE LAS SOCIEDADES ECONÓMICAS DE AMIGOS DEL PAÍS

7. Seres humanos, partes del cuerpo (27 ocurrencias)

mujer (7), corazón (5), mano (4), hombre (3), niño (3), pobre (2), busto (2), cabeza (1)

8. Representación de la ciudad (26 ocurrencias)

escudo coronado (7), ciudad fortificada (6), torre (4), armas (3), escudo (1), fielato (1), acueducto (1), palmera (1), volcán (1), puente (1), sierra (1)

9. Atributos de la Marina y de la pesca (25 ocurrencias) barco (5), ancla (4), mar (2), anillo (2), cuerda (2), mástil (1), vela (1), brújula (1), red (1), nudo (1), pescado (1), cesta (1), gobernalle (1), timón (1), tridente (1)

10. Autoridad, religión (21 ocurrencias) laurel (5), rey (4), angelito (2), reina (1), obispo (1), iglesia (1), altar (1), cáliz (1), vasija (1), cetro (1), venera (1), disciplinas (1), nube (1)

\section{Insectos (4 ocurrencias)}

enjambre (1), colmena (1), abejas (1), hormigas (1)

Un primer grupo, que calificaremos de marco estético podría reunir los campos 2, 7, 11 (Elementos ornamentales, Seres humanos, partes del cuerpo, Insectos), que representan en gran parte elementos utilizados de manera metafórica, cuyo sentido primero es totalmente transparente en beneficio del sentido figurado. (74/335, es decir un 22\%).

Un segundo grupo, que llamaremos economia, reune los signos que representan las actividades en relación con la economía (campos $1,3,5,9$ ), representando el $46 \%$ del total (154/335).

Como en el caso del mensaje lingüístico, aparece de nuevo la idea de progreso y abundancia (campo 4, 33 ocurrencias) y el entendimiento (campo 6, 28 ocurrencias) osea un total de $46 / 335$ o el $18 \%$ del total. Este grupo reune elementos que calificaremos de medios y metas.

El último conjunto, que llamaremos, emisores del mensaje, reagrupa los campos 8 y 10, o sea las representaciones de la ciudad y las del poder y de la autoridad.

Los emblemas no son la realidad, sino conjuntos simbólicos. Sin embargo, el primer nivel de lectura nos puede dar una idea, aunque muy imprecisa, de las técnicas agrícolas gracias por ejemplo al campo 1. La presencia del arado común sin juego delantero demuestra que el arado de tipo moderno no era muy usado, siendo su desarrollo en España muy lento ${ }^{28}$. Lo mismo se puede decir en cuanto a la

28. Véase el informe de Don Agustín Cordero:"Descripción del arado inglés, y otros instrumentos de agricultura (1778)", p. 93 sq in Memorias de la Real Sociedad Económica Matritense, Madrid, Imprenta Sancha, t. 3. El autor nota, p 96, entre otras cosas que "Este instrumento es muy compuesto, y de dificultosa ejecución, para nuestros artifices, porque se compone de mucho número de piezas bastante extrañas, y al parecer dificultosas, y el coste de él será excesivo”. 
hoz. Este instrumento tradicional fue reemplazado por la guadaña sólo en el siglo XIX. En este caso, se trata de un problema de rendimiento, independiente de la técnica. En efecto, las dos herramientas existían desde la Edad Media. La guadaña permitía un trabajo más rápido, pero desperdiciaba mucho más grano que su competidora. Sustituyó la hoz sólo cuando, con rendimientos más altos, se pudo compensar esta pérdida debida a la velocidad ${ }^{29}$.

Obviamente esta lectura sólo puede aportar informaciones fragmentarias sobre las técnicas del siglo XVIII. Además, los signos fueron escogidos cuidadosamente por los creadores de los emblemas. Se deben sobre todo analizar como objetos simbólicos.

Análisis de los mensajes icónicos: El mensaje icónico simbólico o la imagen connotada. El mensaje simbólico es bastante más complejo que el mensaje literal. Connota un código cultural que sirve de referencia común y como en el caso del mensaje lingüístico, vuelve a aparecer el código cultural de las Luces hispanas. Sin embargo, este código se ha de considerar como una realidad histórica nacida de unas estructuras sociales y económicas muy precisas.

Al nivel cultural, considerando el primer y el tercer grupo (marco estético y medios y metas) -respectivamente los campos 2, 7, y 11 y los campos 4 y 6-, aparecen elementos representativos tradicionales combinados con elementos más modernos.

Las veintidós ocurrencias de la cornupia son el mejor ejemplo. En la tradición grecolatina "es símbolo de fecundidad y de felicidad. Llena de granos y frutas, boca arriba y no boca abajo como en el arte moderno, es emblema de numerosas deidades: Baco, Ceres, los Ríos, la Abundancia, la Constancia, la Fortuna". Pero en los emblemas estudiados, tiene también su "significado moderno de atributo más que de símbolo de la liberalidad, de la felicidad pública" ${ }^{130}$. Casi lo mismo se puede decir del caduceo ( 7 ocurrencias) y de Mercurio, padre de la agricultura y símbolo de la inteligencia industriosa y creadora ( 2 ocurrencias $)^{31}$. En cambio, el campo 6 presenta un mundo simbólico propio de la Ilustración y menos marcado por la tradición grecolatina (aunque aparece Minerva). Una primera galaxia simbólica compuesta por el sol ( 5 ocurrencias), la antorcha (5 ocurrencias), el espejo y la estrella ( 1 ocurrencia), representa el progreso bajo diferentes aspectos, pero todos asociados directa o indirectamente a la Luz. Esos elementos no se pueden disociar de la Ilustración, noción amplia que en el caso de los emblemas de las Sociedades aparece como una creencia en el progreso de la razón, en el desarrollo positivo de la humanidad gracias al conocimiento científico y técnico. El conjunto pertenece a un trasfondo cultural de dimensión europea ${ }^{32}$.

29. BRAUDEL, F. 1979, p 293.

30. CHEVALIER, J. et GHEERBRANT, A. 1982, artículo "corne d'abondance".

31. CHEVALIER, J. et GHEERBRANT,A. 1982, artículos "caducée" et "Hermès".

32. DIDIER, B. 1987, p. 178. 
La repetición del mapa y del globo terráqueo es más compleja. Demuestra primero la importancia de la geografía en el pensamiento de la Ilustración, pero el globo simboliza también la totalidad y la universalidad del saber y del conocimiento. En el primer grupo, el campo $n^{\circ} 2$ es el que más directamente transcribe la estética de la Ilustración. Se caracteriza por una gran sobriedad y la repetición de elementos arquitectónicos y pictóricos propios del neoclasicismo: frisos, ramas, flores, banderolas. Los campos 7 y 11 demuestran la importancia de las figuras alegóricas: mujer drapeada, niños, pero también los insectos, ejemplos perfectos de vida y trabajo en una sociedad organizada (la colmena y el hormiguero).

El campo $\mathbf{n}^{\circ} 3$, donde aparecen instrumentos de dibujo, aunque relacionado con las actividades económicas, tiene también una dimensión simbólica. Ya que las Sociedades fomentaron la creación de escuelas de dibujo "técnico", parece normal la mención de los atributos de esta actividad (compás, regla, escuadra). Sin embargo muy interesante es la dimensión simbólica de dichos objetos. El compás es "símbolo del dinamismo constructor, el atributo de las actividades creadoras". Asociado con la escuadra, remite a la representación de la perfección (del cuadrado y del círculo). La regla tiene un sentido casi idéntico, "instrumento por excelencia de la construcción, pues de la manifestación universal" ${ }^{33}$. La presencia de los instrumentos de dibujo permite una doble lectura: por una parte una voluntad de desarrollar una nueva pedagogía del dibujo y por otra, una voluntad de construir cosas nuevas según el espíritu de perfección matemática y geométrica de la Ilustración.

El punto de vista, digamos geográfico, aparece claramente cuando se analiza el cuarto grupo, los emisores del mensaje de progreso a través de los emblemas. La heráldica marca fuertemente las representaciones de la ciudad ( 8 escudos, 3 armas) pero es interesante notar la ciudad fortificada y la torre que se refieren siempre a la representación heráldica pero que también definen la ciudad como un espacio particular, delimitado por sus murallas y dominador del campo circundante: Lucena, Valladolid, Puerto Real, siendo en este último ejemplo un escudo el que domina el campo cultivado. Otras ciudades se evocan de manera topográfica o histórica, con la utilización de un elemento de las armas: el acueducto en Segovia, la palmera en Palma de Mallorca, el volcán en la Laguna, el puente en Logroño. De todos modos, al contrario del campo, la ciudad es casi siempre representada por elementos originales que marcan su identidad, sus raíces en el espacio y en la historia. Las Sociedades son productos de la ciudad. A través de los emblemas, definen los centros urbanos como espacios particularizados y particulares mientras que el campo -el Otro- siempre se considera de manera genérica y abstracta. Para resumir, se podría decir que para los Amigos del País estaban las ciudades (su ciudad) y el Campo (y no los, o sus, campos).

33. ChEVALIER, J. et GHEERBRANT,A. 1982, artículos "compas", "équerre", y "règle". 
Si analizamos ahora el segundo grupo (economía), éste parece, a primera vista, una evidencia. Nada extraño que Sociedades Económicas elaboren sus emblemas a partir precisamente de elementos que evocan actividades económicas. Sin embargo, la repetición de unos signos como la ausencia de otros revela una perspectiva subjetiva.

En la agricultura por ejemplo, se nota la ausencia casi total de referencias a la ganadería (sólo dos ocurrencias). Cuanto más sorprendente que el sector representaba más de la cuarta parte del producto agrícola bruto (P.A.B.) ${ }^{34}$. Lo mismo para la viticultura ( 3 ocurrencias), mientras que el vino, en valor comercial era de hecho el segundo producto de la agricultura española ${ }^{35}$. Al contrario, el trigo y la labranza son evocados de manera masiva ( 42 ocurrencias), a menudo por la asociación arado/hoz (Ávila) o arado/trigo (Valladolid). Esos signos son una construcción simbólica tradicional, constituida por la asociación de la fertilización (arado, azadón, laya) y de la fecundidad (hoz, trigo) ${ }^{36}$. Esa distorsión respecto a la realidad se explica sin duda por la presión del contexto económico propio del periodo considerado.

En efecto, por una parte el fuerte crecimiento demográfico combinado con una carencia de tierras laborables libres plantea el problema del abastecimiento regular en granos para el conjunto de la población y más precisamente de los centros urbanos. Para la élite urbana, a la que pertenecía la mayoría de los fundadores de Sociedades, una producción importante y regular de cereales panificables era una garantía de seguridad: se podía así evitar la afluencia de pobres a las ciudades en los años de crisis de subsistencia. El fenómeno era temido ya que podía desembocar en violentos motines, que al final del siglo XVIII tomaron un cariz cada vez más violento contra el orden establecido ${ }^{37}$. Por otra parte, los estamentos privilegiados poseían un monopolio casi completo sobre el comercio de granos. En los periodos de crisis, el producto era objeto de fuertes especulaciones, en todos casos muy lucrativas, sobre todo en las provincias interiores cuyas dificultades de abastecimiento llegaban a ser dramáticas ${ }^{38}$.

La viña era al contrario criticada porque competía con los cereales -muy conocidos son los textos de ilustrados sobre el tema ${ }^{39}-$, aunque hubo excepcio-

34. La ganadería representa en los años 1780 aproximadamente el 26,4\% del P.A.B. MARTí, M. 1994, chapitre 3.

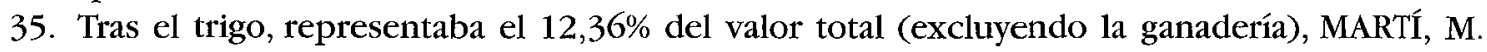
1994, chapitre 3 .

36. CHEVALIER, J. et GHEERBRANT, A. 1982, en los artículos de los símbolos citados.

37. Véase los diferente ejemplos reunidos en MARTÍ, M. 1994, chapitre 2: "Deux espaces antagoniques et complémentaires".

38. MAR'TÍ, M. 1994, chapitre 4: Le blé.

39. El primero y más famoso fue el padre FEIJOO, J. 1989, pp. 274-275: "Es constante que de algún tiempo a esta parte se ha aumentado considerablemente en España la cosecha de vino y minorado la de pan. En tierras donde se cogía mucho pan y poco o ningún vino, hay mucho vino y poco o ningún pan. Pero también es constante que el público es notablemente perjudicado en esto. La carestía de vino, poco o ningún daño hace a un reino; la de pan puede destruirle, puede despoblarlo. 
nes como la Sociedad de Logroño cuya creación respondía en gran parte a las preocupaciones de los grandes cosecheros de la ciudad ${ }^{40}$.

Se atacaba también la ganadería trashumante y las leyes que la protegían. En el Discurso preliminar de las Memorias de Sociedad Económica Matritense, Campomanes apuntaba que "las leyes pecuarias se han ido oponiendo incesamente a los nuevos rompimientos de los terrenos incultos para facilitar el aumento de sus rebaños" $"$.

Los emblemas no reflejan pues una situación agrícola real sino más bien una agricultura soñada, basada en gran parte en la producción cerealista. Esta representación simbólica de la agricultura es influenciada por la coyuntura económica, cuya principal característica es el alza de los precios del trigo y de las tierras panificables, fenómeno a la vez peligroso y lucrativo para la mayoría de las élites urbanas $^{42}$.

Además, los signos revelan el punto de vista social a partir del que se elaboraron los emblemas: el campo y el campesino no aparecen, y cuando éste se menciona, no trabaja. Son las herramientas las que figuran la agricultura y no los hombres o los espacios. Es obvio que el código de representación (arado, hoz) privilegia la tradición simbólica grecolatina, pero demuestra también la transformación del campo en ente abstracto. Las Sociedades se van a interesar en las técnicas, las herramientas pero no en los hombres ocultando así el problema social $^{43}$. El acto de producción, el trabajo del campesino, desaparece completamente, sólo aparece la herramienta y los productos. La imagen de la agricultura que proponen las Sociedades es conservadora, y el progreso reivindicado es únicamente técnico y no social.

En cuanto a los signos que figuran la industria, se refieren a una actividad esencialmente doméstica, una producción manufacturera de pequeño tamaño, casi siempre asociada con la agricultura. De hecho, esos emblemas tienen como texto de referencia los Discursos de Campomanes. En su reflexión, subraya el ministro que "la Agricultura sin artes es lánguida, porque la mujer, los hijos y los niños de un labrador, donde no se ocupan en las fábricas, son una carga, aunque indispensable, que abruma al jornalero y enflaquece al labrador más acomodado" ${ }^{4}$. Pensaba que la actividad manufacturera era sólo un complemento de la

Pero faltando el pan, ¡ay, Dios!, ¡qué triste qué funeste, qué horrible teatro es todo un reino! Todo es lamento, todo es ayes, todo gemidos. Despuéblanse los lugares pequeños y se pueblan de esqueletos los mayores".

40. ALONSO CASTROVIEJO, J.A. 1991.

41. Real Sociedad Económica Matritense, Memorias, Madrid, Imprenta Sancha, t 1, Discurso preliminar, $\mathrm{p}$ XXVIII.

42. MARTÍ, M. 1994, chapitre 3: L'agriculture.

43. Véase el artículo de ARGEMÍ, LL. 1985. En sus conclusiones insiste en particular en el hecho de que los ilustrados y la nueva agronomía tenían más bien una concepción técnica y no social de la agricultura.

44. RODRÍGUEZ DE CAMPOMANES, P. 1975, p. 50. 
agricultura, que permitiría ocupar la mano de obra sobrante en el campo y no competir con las actividades agrícolas. Este tipo de producción que debe desarrollarse en los pueblos mismos, era forzosamente de pequeño tamaño "siempre que las familias empleen su tiempo sobrante, o las personas que no pueden ir al campo, en estas manufacturas, no se disminuye el número de labradores en el Estado [...] aquellas fábricas que arrancan las familias de la labranza son perjudiciales en las aldeas y lugares chicos, pues es cosa observada que el fabricante nunca vuelve a la penosa fatiga del arado" . Para el ministro, "el verdadero interés del estado consiste en mantener dispersa la industria en caseríos y lugares chicos" $"$. Los talleres dispersos evitan las concentraciones de hombres y limitan así las posibilidades de disturbios públicos, idea que se puede relacionar con la preocupación por la producción abundante de trigo. Además, este punto de vista, que trasparece en los emblemas defiende de manera más o menos consciente los intereses de la clase propietaria. En efecto, las manufacturas importantes que absorbían parte de los jornaleros, disminuían la oferta de mano de obra en el mercado del trabajo, aumentando así el coste del trabajo agrícola. Cataluña fue marcada por el fenómeno; Campomanes apuntaba que "en Cataluña conviene fomentar las aldeas, trasladando a ellas mucha parte de la industria que se va a las ciudades, en perjuicio de las aldeas y de los campos" ${ }^{37}$. Como para la agricultura, el punto de vista es conservador: se trata de defender un orden económico inmóvil, en relación con técnicas productivas casi idénticas. Ni siquiera se plantea un progreso de la agricultura que permitiera liberar mano de obra para la producción manufacturera. Aparece aquí la ambigüedad de la noción de progreso, un progreso figurado por el tercer grupo de signos (campos 4 y 6), a la vez meta del trabajo de las Sociedades y medio para lograr la felicidad pública. Para la Ilustración se trata más bien de un progreso enfocado a partir del punto de vista de los estamentos privilegiados. Un progreso que quiere ser puramente técnico, pero también limitado, pues una revolución tecnológica pudiera desequilibrar todo el sistema económico.

\section{CONCLUSIÓN}

Las Sociedades aparecen pues como instituciones complejas. Su desarrollo, a menudo rápido y espontáneo, la unión entre nobles, plebeyos y eclesiásticos se explica por un clima intelectual favorable y una coyuntura económica propicia al desarrollo. La presencia de esas asociaciones en los grandes centros urbanos y en las regiones de mayorazgos y manos muertas demuestran que son ante todo las clases propietarias, cuando no el Estado, los que impulsaron el movimiento.

45. RODRÍGUEZ DE CAMPOMANES, P. 1975, p. 56.

46. RODRÍGUEZ DE CAMPOMANES, P. 1975, p. 76.

47. RODRÍGUEZ DE CAMPOMANES, P. 1975, p. 76. Véase también a VILAR, P. 1962, p. 110. 
Sin embargo al cabo de un decenio, el funcionamiento de dichas instituciones será dificultado por factores internos y externos.

Analizando los emblemas y lemas se llega a conclusiones interesantes en cuanto al conocimiento de las Luces hispanas. En su tentativa de autodefinición que proponen dichas asociaciones aparecen tres elementos formales importantes:

- Unas referencias a la cultura grecolatina, uno de los tópicos de las Luces europeas. Ese trasfondo tradicional sirve de marco a la expresión de ideas nuevas.

- La reivindicación de un ideario ilustrado donde dominan la fe en la razón, la técnica, la enseñanza, que permitirán alcanzar el progreso y la abundancia.

- Un punto de vista urbano y abstracto sobre el campo que revela el empleo del código cultural grecolatino así como los emblemas que privilegian el espacio urbano con todas sus particularidades

Por otra parte, la evolución de la coyuntura económica y social influenció sin duda ninguna en la composición de los emblemas y la representación de la agricultura: se nota la predominancia de la labranza respecto a la viticultura y la ganadería. Así aparece la visión de la élite urbana, que posee la mayor parte de las tierras y que considera el campo a partir de su propio punto de vista, proyectando en él sus sueños de desarrollo económico y de beneficios.

Por otra parte, esas representaciones simbólicas revelan una posición conservadora: se oculta el problema social en beneficio de una preocupación técnica y la noción de progreso queda ambigua. Se trata ante todo de mejorar las técnicas y modos de producción tradicionales. Aquí estriba quizá una de las contradicciones esenciales de la Ilustración española: se pretendía actuar en el campo de la técnica sin modificar en nada la estructura social.y paradójicamente, reivindicando la modernidad, era forzoso limitar las innovaciones técnicas que hubieran podido acarrear transformaciones sociales mayores ${ }^{48}$.

48. Indirectamente, cualquier transformación técnica mayor implica transformaciones sociales. En la España del siglo XVIII, como lo apunta Argemí.ARGEMI, L1. 1985, p 39: "La mejora de las técnicas exigía la ley agraria, y la ley agraria necesitaba el complemento de la modernización técnica. Por ello una vez se ha limitado el alcance de la "revolución agrícola" que suponía la "nueva agricultura", incluso la reforma técnica que quedaba era de alcance reducido: procurar que se haga bien lo que corresponde a la práctica tradicional". 


\section{BIBLIOGRAFÍA}

ALONSO CASTROVIEJO, J.A. 1991

Problemática agraria y solución burguesa, Logroño, 1750-1833, Logroño.

ANES, G. 1972

Economía e Ilustración en la España del siglo XVIII, Barcelona.

ARGEMÍ, L1. 1985

"Agronomía y revolución agraria en España": ARGEMÍ, Ll. y LLUCH, E., Agronomía y fisiocracia en España (1750-1820), Valencia.

BARTHES, $\mathbf{R}$.

"Rhétorique de l'image": Communications 4, pp. 40-51.

BRAUDEL, F. 1979

Civilisation matérielle, économie et capitalisme, XVe-XVIIIe siècle, Paris, tome 1.

CHAUNU, P. 1971

La civilisation de l'Europe des Lumières, Paris.

CHEVALIER, J. et GHEERBRANT,A. 1982

Dictionaire des symboles, Paris.

DEMERSON, J. 1969

La real sociedad económica de Valladolid (1784-1808), Valladolid.

DEMERSON, P., DEMERSON, J.AGUILAR PIÑAL, F. 1974

Las Sociedades Económicas de Amigos del País en el siglo XVIII. Guía del investigador, San Sebastián.

DIDIER, B. 1987:

Le siècle des Lumières, Paris.

DOMERGUE, L. 1969

Jovellanos à la Société Économique des Amis du Pays du madrid, 1778-1790, Toulouse.

FEIJOO, B.J. 1989

Teatro crítico universal, Madrid.

LUCIENNE, D. 1969

Jovellanos à la Société Économique des Amis du Pays du Madrid 1778-1790, Toulouse.

MARTÍ, M. 1994

Ville et campagne dans l'Espagne des Lumières (1746-1808), Thèse de Doctorat, Saint Étienne.

PORCHER, L. 1976

Introduction à une sémiotique des images. Sur quelques exemples d'images publicitaires, Paris.

RODRÍGUEZ DE CAMPOMANES, P. 1975

Discurso sobre el fomento de la industria popular; Discurso sobre la educación popular de los artesanos y su fomento, ed. de REEDER, J. Madrid. 
EMBLEMAS Y LEMAS DE LAS SOCIEDADES ECONÓMICAS DE AMIGOS DEL PAÍS

SOUBEYROUX, J. 1981

"Ordre social et subversion de l'ordre dans les caprices de Goya": Imprévue 2, pp. 107-137, Montpellier

VELÁZQUEZ MARTÍNEZ, 1989

La Sociedad económica de Amigos del País de Murcia, la Institución los bombres $y$ el dinero (1777-1820), Murcia.

VERGNES, $\mathbf{R}$.

"Dirigisme et libéralisme économique à la Sociedad Económica de Madrid (de l'influence de Jovellanos)": Bulletin Hispanique LXX, pp. 300-341.

VILAR, P. 1962

La Catalogne dans l'Espagne Moderne, t 2, Barcelona. 
